\title{
Clinical characteristics of patients with suspected cardiac chest pain and angiographically normal coronary arteries in a secondary care hospital
}

\author{
T. S. de Lange ${ }^{1}$ R. Y. G Tijssen ${ }^{2}$ P. Damman ${ }^{2}$ P. F. M. M. van Bergen ${ }^{1}$
}

Published online: 20 April 2017

(c) The Author(s) 2017. This article is an open access publication.

\begin{abstract}
Background An important number of patients with suspected cardiac chest pain have non-obstructive coronary artery disease. Our purpose was to describe the clinical characteristics of patients with normal or near-normal coronary arteries in routine cardiological practice in a secondary care hospital.

Methods In 2013, consecutive patients referred for invasive coronary angiography with suspected cardiac chest pain were analysed at a single-centre (Westfriesgasthuis, Hoorn, the Netherlands). Coronary arteries were defined as normal or near-normal if they showed no stenosis or only slight wall irregularities on visual assessment. Patients with a final non-cardiac diagnosis for the chest pain were excluded.

Results A total of 558 patients were included. Of these, 151 (27\%) showed normal or near-normal coronary arteries on visual assessment. This group of patients were significantly more often female $(p<0.001)$, younger $(p<0.001)$ and non-diabetic $(p=0.002)$. Forty percent of hospitalised patients who had normal or near-normal coronary arteries at coronary angiography showed an elevated troponin.

Conclusion In routine cardiological practice, around 1 out of 4 patients with suspected cardiac chest pain undergoing invasive angiography had normal or near-normal coronary arteries. We suggest that premenopausal women with
\end{abstract}

P. F. M. M. van Bergen

p.vanbergen@westfriesgasthuis.nl

1 Department of Cardiology, Westfriesgasthuis, Hoorn, The Netherlands

2 Heart Center, Academic Medical Center, University of Amsterdam, Amsterdam, The Netherlands suspected cardiac chest pain could be considered for noninvasive coronary imaging as a first step in clinical practice.

Keywords Chest pain - Normal coronary arteries · Troponin

\section{Introduction}

Stable angina pectoris and acute coronary syndrome (ACS) are two clinical manifestations of coronary artery disease (CAD). In accordance with clinical practice guidelines, most of these patients are referred for intracoronary evaluation [1-3]. Previous studies show that approximately $10 \%$ of non-ST-elevation myocardial infarction (non-STEMI) patients and $30-60 \%$ of patients with stable AP have no CAD [4-8]. Moreover, other studies and registries have shown that up to $39 \%$ of patients with suspected CAD may have visually normal or near-normal coronary arteries on invasive coronary angiography [9, 10]. More recently, noninvasive imaging techniques have confirmed that about half of patients with a clinical indication for CAD evaluation had no apparent coronary disease [11-13]. However, recent data on normal coronary arteries in invasive angiography in contemporary routine cardiological practice are lacking. In this paper we describe the clinical characteristics of consecutive patients with normal coronary arteries at invasive coronary angiography for suspected cardiac chest pain at a secondary care centre. 


\section{Methods}

\section{Patient population}

The study population consisted of patients who were referred for coronary angiography because of suspected cardiac chest pain between January 1, 2013 and January 1, 2014 at the Westfriesgasthuis, a medium large secondary care centre in Hoorn, the Netherlands. Patients with STEMI were excluded because they were directly referred to a primary PCI centre [3]. Peri-procedural patient characteristics, laboratory results, ECGs and data from coronary angiograms were collected retrospectively. This study complies with the Dutch Medical Research Involving Human Subjects Act.

\section{Data analysis}

Based on the results of the coronary angiogram, patients were classified into two groups: 1) patients with visually normal or only minimal coronary artery stenosis, and 2) patients with more extensive coronary disease. The extent and severity of CAD was assessed by routine visual assessment by the operator. Patients were diagnosed with stable angina, unstable angina or non-STEMI based on clinical data [1-3]. One-year outcomes included coronary revascularisation by either PCI or CABG, and survival during follow-up. Outcomes were collected from electronic patient files.

\section{Statistical methods}

Continuous variables were expressed as mean \pm standard deviation and categorical data were expressed as numbers (percentage). Differences between patient groups were analysed with a chi-square or a Fisher's exact test for categorical variables and independent samples t-test for continuous variables; two-sided probability of less than 0.05 was considered statistically significant. Multivariate analysis was performed using binary logistic regression. Data were analysed using IBM SPSS statistics for Windows version 19.0 (IBM Corp., Armonk NY).

\section{Results}

Between January 1, 2013 and January 1, 2014, a total of 817 patients underwent invasive coronary angiography (Fig. 1) of whom $577(71 \%)$ underwent coronary angiography because of suspected cardiac chest pain. During one-year follow-up, 19 patients were excluded because of a definitive non-coronary diagnosis of their chest pain. Consequently, 558 patients were analysed; 151 patients had normal or

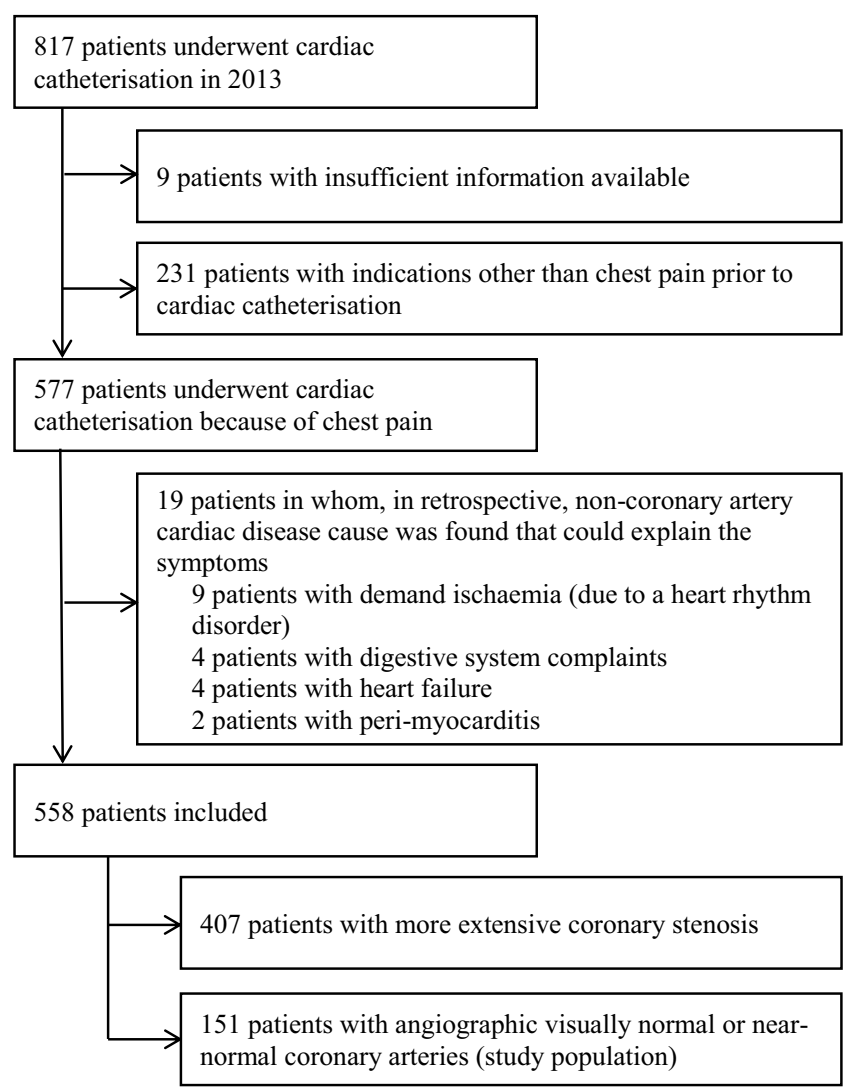

Fig. 1 Flowchart

near-normal coronary arteries, and 407 patients had more extensive CAD (Fig. 1).

Baseline characteristics and 1-year outcomes of the two patient groups are shown in Table 1. Patients with visually normal arteries showed significant differences compared with patients with more extensive coronary disease with regard to age (62.6 vs 66.7 years, $p<0.001)$, female gender $(54 \%$ vs $27 \%, p<0.001)$ and diabetes $(11 \%$ vs $23 \%, p=0.002)$. Consequent multivariate analysis showed that on coronary angiography lower age, female gender and absence of diabetes were independent predictors of normal coronary arteries.

Table 2 shows the results according to defined clinical diagnosis in both patient groups. All three diagnostic categories encompassed a substantial number of patients with normal or near-normal coronary arteries, predominantly women. None of the patients in the normal coronary artery group had a coronary revascularisation procedure during follow-up versus $30 \%$ in the coronary artery stenosis group. Furthermore, one-year survival rate was $99.3 \%$ in the normal coronary artery group and $95.8 \%$ in the group of patients with coronary stenosis. The cause of death of the deceased patient in the normal coronary artery group was non-cardiac disease. 
Table 1 Patient characteristics by no angiographic visual abnormalities and 1-year outcomes
Table 2 Summary of subgroup analyses according to clinical diagnosis

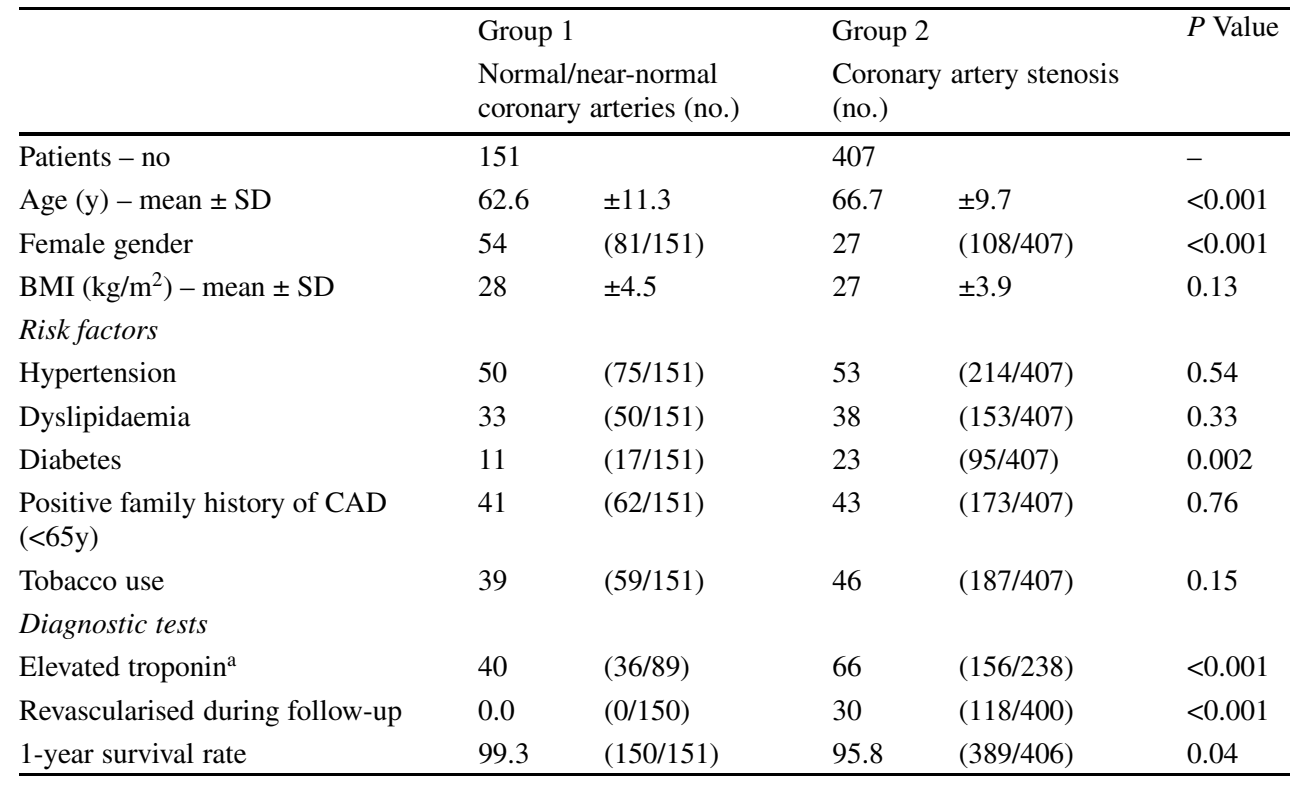

$B M I$ body mass index, $C A D$ coronary artery disease

a Troponin $\mathrm{T}>0.013 \mu \mathrm{g} / \mathrm{L}$ with a significant increase in the second value

\begin{tabular}{lccccc}
\hline Subgroup & $\begin{array}{l}\text { Group 1 } \\
\text { Normal/near-normal } \\
\text { coronary arteries }\end{array}$ & $\begin{array}{l}\text { Group 2 } \\
\text { Coronary artery stenosis }\end{array}$ & $P$ Value \\
\hline $\begin{array}{l}\text { Patients with stable angina } \\
\text { Patients }\end{array}$ & $27 \%$ & $(n=62)$ & $73 \%$ & $(n=169)$ & - \\
$\begin{array}{l}\text { Female gender } \\
\text { Patients with unstable angina pectoris }\end{array}$ & $50 \%$ & $(31 / 62)$ & $27 \%$ & $(47 / 169)$ & 0.002 \\
$\begin{array}{l}\text { Patients } \\
\text { Female gender }\end{array}$ & $39 \%$ & $(n=53)$ & $61 \%$ & $(n=82)$ & - \\
$\begin{array}{l}\text { Patients with non-STEMI } \\
\text { Patients }\end{array}$ & $51 \%$ & $(27 / 53)$ & $23 \%$ & $(19 / 82)$ & 0.001 \\
Female gender & $19 \%$ & $(n=36)$ & $81 \%$ & $(n=156)$ & - \\
\hline
\end{tabular}

Patients with unstable AP and non-STEMI were all hospitalised

\section{Discussion}

This study shows that approximately 1 out of 4 patients with suspected cardiac chest pain in routine cardiological practice in a secondary care hospital has visually normal coronary arteries on invasive coronary angiography and that these patients are younger, more often female and nondiabetic than patients with more extensive CAD.

\section{Suspected cardiac chest pain andnormal or near- normal coronary arteries}

Several studies have previously reported on patients with suspected cardiac chest pain and normal coronary arteries on invasive coronary angiogram [9, 14-16]. Normal coronary arteries, showing no apparent CAD, are associated with a significantly lower 1-year risk of myocardial infarction (MI) and all-cause mortality compared with nonobstructive CAD [6]. Our results confirm that the prognosis is better in patients with minimal CAD than in patients with more extensive CAD. More recently, studies using a non-invasive imaging technique such as coronary computed tomography angiography ormyocardial perfusion imaging have confirmed both normal coronary arteries and non-obstructive coronary disease in patients with suspected $\mathrm{CAD}$, with an impaired prognosis in patients with increasing severity of coronary disease [13, 17-22].

Possible causes of chest pain in patients with normal coronary arteries are numerous and include plaque erosion, coronary microvascular disease, endothelial dysfunction, myocardial bridging and coronary artery spasm [23-25]. Forty percent of hospitalised patients with normal coronary arteries in our study population had a clinically significant rise in troponin, indicating myocardial infarction. Earlier 
studies showed that a prolonged episode of coronary artery spasm can lead to elevated troponin and myocardial infarction [26-28]. Although coronary spasm is sometimes believed to be restricted to Asian patients [29-31], the coronary artery spasm in patients with acute coronary syndrome study (CASPAR) shows that coronary spasm can be a frequent cause of ACS in a European population with an excellent prognosis for survival and coronary events after three years [32, 33].

\section{Gender differences}

Previous studies have shown that chest pain syndromes are more common in women than in men and are less related to the presence of atherosclerosis in the large epicardial coronary arteries [17, 34-37]. Gender-specific factors that affect the development and prognosis of coronary heart disease are diverse but are becoming increasingly clear [38, 39]. Our multivariate analysis confirmed that female gender itself was independently associated with normal coronary arteries in our patients with suspected CAD. Yet, most of the female patients with normal coronary arteries in our patient population were hospitalised for unstable AP or nonSTEMI, suggestive of a temporary - but haemodynamically relevant - coronary obstruction.

Vasospasm of the epicardial arteries, microvascular coronary dysfunction (non-endothelial dependent), endothelial dysfunction and higher endothelial shear may all attribute to the higher prevalence of angina and adverse cardiovascular events in women compared with men [40-42]. Our data show that the 1-year prognosis for patients with suspected CAD and normal coronary arteries is good for both men and women.

\section{Implications for clinical practice}

Recent data show that cardiac MRI or Myocardial Perfusion Imaging (MPI) can help to reduce the use of coronary angiography in a general population of patients with suspected CAD [43]. Our data show that younger premenopausal women with suspected chest pain could be considered for non-invasive coronary imaging as a first step in the diagnostic process.

\section{Strengths and limitations of this study}

This study included consecutive patients undergoing invasive angiography at a non-intervention centre, therefore no additional intracoronary evaluation such as intravascular ultrasound (IVUS) or optical coherence tomography (OCT), could be performed to assess angiographic nonvisible atherosclerosis and plaque erosion. Neither could we establish functional coronary disease due to thelack of a spasm provocation test facility at our hospital.

Also, the introduction of highly sensitive troponin assays has improved the accuracy of diagnostic testing for myocardial necrosis and thereby increased the number of patients referred for additional intracoronary examination, in particular in women [44-46]. However, this study reflects a real-life cohort of patients with stable AP or ACS in a secondary care hospital using establised care protocols according to the latest clinical practice guidelines.

\section{Conclusion}

This study demonstrates a high prevalence of normal or near-normal coronary arteries in patients with suspected cardiac chest pain in routine cardiological practice in a secondary care hospital today. These patients were more often female, younger or non-diabetic and had excellent 1-year survival rate and coronary revascularisation rate

Consequently, we suggest that premenopausal females who have suspected CAD could be considered for noninvasive cardiac imaging as a first step in clinical practice.

Funding This study was not funded.

Conflict of interest T.S. de Lange, R.Y.G. Tijssen, P. Damman and P.F.M.M. van Bergen declare that they have no competing interests.

Open Access This article is distributed under the terms of the Creative Commons Attribution 4.0 International License (http:/ creativecommons.org/licenses/by/4.0/), which permits unrestricted use, distribution, and reproduction in any medium, provided you give appropriate credit to the original author(s) and the source, provide a link to the Creative Commons license, and indicate if changes were made.

\section{References}

1. Task Force Members, Montalescot G, Sechtem U, et al. 2013 ESC guidelines on the management of stable coronary artery disease: the Task Force on the management of stable coronary artery disease of the European Society of Cardiology. Eur Heart J. 2013;34:2949-3003.

2. Roffi M, Patrono C, Collet JP, et al. 2015 ESC Guidelines for the management of acute coronary syndromes in patients presenting without persistent ST-segment elevation. Eur Heart J. 2016;37:1101-6.

3. Task Force on the management of ST-segment elevation acute myocardial infarction of the European Society of Cardiology (ESC), Steg PG, James SK, Atar D, et al. ESC Guidelines for the management of acute myocardial infarction in patients presenting with STsegment elevation. Eur Heart J. 2012;33:2569-619.

4. Yilmaz A, Sechtem U. Angina pectoris in patients with normal coronary angiograms: current pathophysiological concepts and therapeutic options. Heart. 2012;98:1020-9.

5. Patel MR, Chen AY, Peterson ED, et al. Prevalence, predictors, and outcomes of patients with non-ST-segment elevation myocardial infarction and insignificant coronary artery disease: results from the Can Rapid risk stratification of Unstable angina patients Suppress 
ADverse outcomes with Early implementation of the ACC/AHA Guidelines (CRUSADE) initiative. Am Heart J. 2006;152:641-7.

6. Maddox TM, Stanislawski MA, Grunwald GK, et al. Nonobstructive coronary artery disease and risk of myocardial infarction. JAMA. 2014;312:1754.

7. Patel MR, Dai D, Hernandez AF, et al. Prevalence and predictors of nonobstructive coronary artery disease identified with coronary angiography in contemporary clinical practice. Am Heart J. 2014;167:846-852.e2.

8. Planer D, Mehran R, Ohman EM, et al. Prognosis of patients with non-ST-segment-elevation myocardial infarction and nonobstructive coronary artery disease: propensity-matched analysis from the acute catheterization and urgent intervention triage strategy trial. Circ Cardiovasc Interv. 2014;7:285-93.

9. Patel MR, Peterson ED, Dai D, et al. Low diagnostic yield of elective coronary angiography. N Engl J Med. 2010;362:886-95.

10. Kemp HG, Kronmal RA, Vlietstra RE, Frye RL. Seven year survival of patients with normal or near normal coronary arteriograms: a CASS registry study. J Am Coll Cardiol. 1986;7:479-83.

11. Achenbach S, Daniel WG. Cardiac imaging in the patient with chest pain: coronary CT angiography. Heart. 2010;96:1241-6.

12. Schuijf JD, Achenbach S, de Feyter PJ, Bax JJ. Current applications and limitations of coronary computed tomography angiography in stable coronary artery disease. Heart. 2011;97:330-7.

13. Rossi A, Dharampal A, de Feyter PJ. Coronary CT angiography for patients with suspected coronary artery disease. Heart. 2014;100:976-84.

14. Kaski JC. Pathophysiology and management of patients with chest pain and normal coronary arteriograms (cardiac syndrome X). Circulation. 2004; 109:568-72.

15. Da Costa A, Isaaz K, Faure E, et al. Clinical characteristics, aetiological factors and long-term prognosis of myocardial infarction with an absolutely normal coronary angiogram; a 3-year follow-up study of 91 patients. Eur Heart J. 2001;22:1459-65.

16. Bugiardini R, Bairey Merz CN. Angina with 'normal' coronary arteries: a changing philosophy. JAMA. 2005;293:477-84.

17. Min JK, Dunning A, Lin FY, et al. Age- and sex-related differences in all-cause mortality risk based on coronary computed tomography angiography findings. J Am Coll Cardiol. 2011;58:849-60.

18. Lin FY, Shaw LJ, Dunning AM, et al. Mortality risk in symptomatic patients with nonobstructive coronary artery disease. J Am Coll Cardiol. 2011;58:510-9.

19. van Werkhoven JM, Schuijf JD, Jukema JW, et al. Anatomic correlates of a normal perfusion scan using 64-slice computed tomographic coronary angiography. Am J Cardiol. 2008;101:40-5.

20. Meijboom WB, Meijs MFL, Schuijf JD, et al. Diagnostic accuracy of 64-slice computed tomography coronary angiography. J Am Coll Cardiol. 2008;52:2135-44.

21. Cheruvu C, Precious B, Naoum C, et al. Long term prognostic utility of coronary CT angiography in patients with no modifiable coronary artery disease risk factors: Results from the 5 year follow-up of the CONFIRM International Multicenter Registry. J Cardiovasc Comput Tomogr. 2016;10:22-7.

22. Schuijf JD, Wijns W, Jukema JW, et al. Relationship between noninvasive coronary angiography with multi-slice computed tomography and myocardial perfusion imaging. J Am Coll Cardiol. 2006;48:2508-14.

23. Camici PG, Crea F. Coronary microvascular dysfunction. N Engl J Med. 2007;356:830-40.

24. Sheikh AR, Wei J, Bairey Merz CN, Beltrame JF. The current state of invasive coronary evaluation and management of patients with angina and nonobstructive coronary arteries - American College of Cardiology 2016. http://www.acc.org/latest-in-cardiology/ articles/2016/05/26/08/31/the-current-state-of-invasive-coronaryevaluation-and-management-of-patients-with-angina-andnonobstructive-coronary-arteries. Accessed 9 Dec 2016.
25. Lee B-K, Lim H-S, Fearon WF, et al. Invasive evaluation of patients with angina in the absence of obstructive coronary artery disease. Circulation. 2015;131:1054-60.

26. Wang C-H, Kuo L-T, Hung M-J, Cherng W-J. Coronary vasospasm as a possible cause of elevated cardiac troponin I in patients with acute coronary syndrome and insignificant coronary artery disease. Am Heart J. 2002;144:275-81.

27. Lip GY, Ray KK, Shiu MF. Coronary spasm in acute myocardial infarction. Heart. 1998;80:197-9.

28. Stern S, Bayes de Luna A. Coronary artery spasm: a 2009 update. Circulation. 2009;119:2531-4.

29. Fukai T, Koyanagi S, Takeshita A. Role of coronary vasospasm in the pathogenesis of myocardial infarction: study in patients with no significant coronary stenosis. Am Heart J. 1993;126:1305-11.

30. Kim MH, Park EH, Yang DK, et al. Role of vasospasm in acute coronary syndrome: insights from ergonovine stress echocardiography. Circ J. 2005;69:39-43.

31. Sueda S, Kohno H, Fukuda H, et al. Frequency of provoked coronary spasms in patients undergoing coronary arteriography using a spasm provocation test via intracoronary administration of ergonovine. Angiology. 2004;55:403-11.

32. Ong P, Athanasiadis A, Hill S, Vogelsberg H, Voehringer $M$, Sechtem U. Coronary artery spasm as a frequent cause of acute coronary syndrome. The CASPAR (Coronary Artery Spasm in Patients With Acute Coronary Syndrome) study. J Am Coll Cardiol. 2008;52:523-7.

33. Ong P, Athanasiadis A, Borgulya G, Voehringer M, Sechtem U. 3-year follow-up of patients with coronary artery spasm as cause of acute coronary syndrome: the CASPAR (Coronary Artery Spasm in Patients With Acute Coronary Syndrome) study follow-up. J Am Coll Cardiol. 2011;57:147-52.

34. Hochman JS, Tamis JE, Thompson TD, et al. Sex, clinical presentation, and outcome in patients with acute coronary syndromes. Global use of strategies to open occluded coronary arteries in acute coronary syndromes IIb investigators. N Engl J Med. 1999;341:226-32.

35. Shaw LJ, Bugiardini R, Merz CNB. Women and ischemic heart disease: evolving knowledge. J Am Coll Cardiol. 2009;54:1561-75.

36. Versteylen MO, Joosen IA, Kietselaer BL, Wildberger JE, Crijns HJ, Hofstra L. Gender difference in the prognostic value of CTA? JACC Cardiovasc Imaging. 2014;7:529-30.

37. Gulati M, Shaw LJ, Bairey Merz CN. Myocardial ischemia in women: lessons from the NHLBI WISE study. Clin Cardiol. 2012;35:141-8.

38. Maas AHEM, Appelman YEA. Gender differences in coronary heart disease. Neth Heart J. 2010;18:598-602.

39. Sharaf B, Wood T, Shaw L, et al. Adverse outcomes among women presenting with signs and symptoms of ischemia and no obstructive coronary artery disease: findings from the National Heart, Lung, and Blood Institute-sponsored Women's Ischemia Syndrome Evaluation (WISE) angiographic core lab. Am Heart J. 2013;166:134-41.

40. Johnson BD, Shaw LJ, Pepine CJ, et al. Persistent chest pain predicts cardiovascular events in women without obstructive coronary artery disease: results from the NIH-NHLBI-sponsored Women's Ischaemia Syndrome Evaluation (WISE) study. Eur Heart J. 2006;27:1408-15.

41. Sedlak TL, Lee M, Izadnegahdar M, Merz CNB, Gao M, Humphries $\mathrm{KH}$. Sex differences in clinical outcomes in patients with stable angina and no obstructive coronary artery disease. Am Heart J. 2013;166:38-44.

42. Patel MB, Bui LP, Kirkeeide RL, Gould KL. Imaging microvascular dysfunction and mechanisms for female-male differences in CAD. JACC Cardiovasc Imaging. 2016;9:465-82.

43. Greenwood JP, Ripley DP, Berry C, et al. Effect of care guided by cardiovascular magnetic resonance, myocardial perfusion scintig- 
raphy, or NICE guidelines on subsequent unnecessary angiography rates. JAMA. 2016;316:1051-60.

44. Weber M, Bazzino O, Navarro Estrada JL, et al. Improved diagnostic and prognostic performance of a new high-sensitive troponin $\mathrm{T}$ assay in patients with acute coronary syndrome. Am Heart J. 2011;162:81-8.
45. Thygesen K, Mair J, Giannitsis E, et al. How to use high-sensitivity cardiac troponins in acute cardiac care. Eur Heart J. 2012;33:2252-7.

46. Shah ASV, Griffiths M, Lee KK, et al. High sensitivity cardiac troponin and the under-diagnosis of myocardial infarction in women: prospective cohort study. BMJ. 2015;350:g7873. 